\title{
DEL CUSCO RENACE LA INTEGRACIÓN ANDINA: LA RESTAURACIÓN DEL PUENTE DE LA ALMUDENAA ${ }^{(*)}$
}

\author{
ANDEAN INTEGRATION IS REBORN FROM CUSCO: THE RESTORATION OF \\ THE LA ALMUDENA BRIDGE
}

\author{
YADIRA GUERRA VERA ${ }^{(\star \star)} Y$ MIGUEL LANDA SIERRA ${ }^{(\star \star)}$ \\ Fecha de recepción: 02 de abril de 2017 \\ Fecha de aprobación: 11 de junio de 2017
}

\section{RESUMEN}

Este artículo presenta una crítica arquitectónica al resultado de la obra de Recuperación y Puesta en Valor del Puente de La Almudena en la ciudad de Cusco, culminada el año 2006. Dicho proyecto parte de la idea general de recuperar físicamente la trayectoria histórica de los caminos pertenecientes al sistema vial inca Qhapaq Ñan, que alguna vez fue la primordial herramienta de integración del entonces Tawantinsuyu. La ejecución de este proyecto significó la renovación de un espacio en franco proceso de deterioro e insalubridad, así como la reapertura del acceso por medio del cual el centro histórico de la ciudad de Cusco se comunica con los territorios del Kuntisuyu o territorios hacia la costa, intervención durante la cual tuvieron lugar nuevos retos y experiencias metodológicas, además de que se gestó una nueva forma de concebir el valor del patrimonio civil público de carácter vial, hasta entonces poco apreciado.

\section{PALABRAS CLAVE}

Qhapaq Ñan, puesta en valor, revitalización urbana

\begin{abstract}
This article presents an architecture critique about the result of the La Almudena Bridge Restoration and Value Enhancement project in the city of Cusco, which ended the year 2006. Said project starts from the idea of physically recovering the historical Inca road system, the Qhapaq Ñan, that was once the crucial integration tool of the then empire of the Tawantinsuyu. The realization of the project also meant the renovation of a space under a marked deterioration and insalubrity process. As well, it caused the reopening of the access through which Cusco communicates with the Kuntisuyu, or coastal, territories. Unexpected challenges and new methodological experiences appeared during the intervention, and a new way to understand the value of public civil transportation heritage was born, previously not truly appreciated.
\end{abstract}

\section{KEYWORDS}

Qhapaq Ñan, value enhancement, urban renewal

(*) Este artículo ha sido extraído de una asignación académica del curso Taller de Conservación del Patrimonio Cultural Arquitectónico de la maestría en Arquitectura, mención en Gestión del Patrimonio Cultural, Centros y Sitios Históricos de la Universidad Nacional San Antonio Abad del Cusco (UNSAAC), dictado por el MSc. Arq. José Hayakawa Casas en febrero de 2017

(**) Arquitecta por la UNSAAC, con maestría en Arquitectura, mención en Gestión del Patrimonio Cultural, Centros y Sitios Históricos por la misma universidad. Su experiencia en el tema de patrimonial ha sido formada por su trabajo en la Municipalidad Provincial del Cusco por más de 14 años. Su labor en esta institución estuvo vinculada con proyectos de restauración patrimonial con apoyo de la Cooperación Española. Posteriormente participó en acciones de registro y catalogación de bienes inmuebles, y laboró como responsable de la formulación del Plan Maestro del Centro Histórico de la ciudad del Cusco. Es miembro de ICOMOS-Cusco desde 2016. Actualmente, es docente en la Facultad de Ingeniería y Arquitectura de la UNSAAC. Contacto: yadiraguerrav@yahoo.es (***) Arquitecto por la UNSAAC, con maestría en Arquitectura, mención en Gestión del Patrimonio Cultural, Centros y Sitios Históricos por la misma universidad. Su experiencia en el tema de patrimonial proviene de su responsabilidad como coordinador de las áreas de Proyectos, Museos y Sistema de Información Geográfica del Proyecto Qhapaq Ñan en Cusco, desde 2001. Es docente universitario de la cátedra Inca Architecture y Heritage Conservation para estudiantes universitarios norteamericanos. Es también supervisor de varios proyectos de valor patrimonial en la Municipalidad del Cusco y en el Ministerio de Cultura, bajo la normativa del Sistema Nacional de Inversión Pública. Es proyectista de la obra Recuperación y Puesta en Valor del Puente de La Almudena, camino del Kuntisuyu. Contacto: mlandasierra@gmail.com 
Muchas de las intervenciones llevadas a cabo en el centro histórico de la ciudad del Cusco corresponden a tipologías arquitectónicas de carácter religioso o civil doméstico. Dichas intervenciones han generado interesantes experiencias, metodologías y procesos de restauración que fungen como ejemplos que posibilitan la estandarización de mecanismos de actuación. Contraria a esta práctica es la ejecución del proyecto de intervención urbana Recuperación y Puesta en Valor del Puente de La Almudena - Camino del Kuntisuyu, desarrollado y ejecutado en la ciudad del Cusco entre los años 2004 y 2006. Dicho proyecto implicó la intervención en un área que contiene un bien cultural inicialmente depreciado o subvaluado, reconocido entonces solo por algunos profesionales, o entendidos en temas patrimoniales viales y arqueológicos. Recién a inicios de este siglo se incorporaron nuevas de ideas de conservación a nivel político y social, y, con posibilidades importantes de conseguir inversión, la intervención comenzó a suscitar un nivel interés general, lo cual le mereció el apoyo de muchas instituciones públicas y privadas, que con diversos objetivos, puntos de vista, funciones y responsabilidades confluyeron en la tarea de recuperación de la intersección de la avenida Del Ejército y la calle Hospital.

En el presente artículo se desarrolla un análisis crítico y valorativo de esta intervención pública, el cual incluye la evaluación del expediente técnico y la posterior intervención. Asimismo, se realiza una valoración del bien cultural 12 años después de su recuperación, donde se resaltan los criterios de intervención aplicados, y se evalúa si realmente se recuperó el bien y se puso efectivamente en valor, así como el impacto social y económico de la intervención en el área, entre otros aspectos.

El análisis se enriquece mediante la recapitulación de la controversia que generó la intervención en cuestión. Esta controversia incluía la necesidad de dar desfogue al nuevo y congestionado tráfico vehicular de la avenida Del Ejército en tanto vía circundante al centro histórico y a su vez futura vía de articulación interdepartamental, y por otro lado, recuperar el camino histórico Qhapaq Ñan del Kuntisuyu, de alto valor patrimonial, pues articulaba la plaza de Armas del Cusco con el océano Pacifico, que confluía transversalmente a este flujo vehicular. ¿Qué hacer?

Se empezó a motivar la participación de los medios de prensa y la atención de la población ante la disyuntiva "patrimonio vs. desarrollo". Así, el entonces Instituto Nacional de Cultura (INC), a través del proyecto Qhapaq Ñan, puso en la palestra la recuperación de los caminos del antiguo Tawantinsuyu. El proyecto de conservación y puesta en valor del puente de La Almudena, ubicado en el eje troncal del camino del Kuntisuyu, resulta de vital importancia para dicha recuperación.

La puesta en uso social del Puente de La Almudena conllevó también a un estudio de otras obras referenciales, aunque de otra índole o tipología, debido a la ausencia de una intervención similar en el ámbito inmediato. Se trata de la única muestra de su tipo, cuya puesta en uso se llevó a cabo sobre la base de la revisión teórica de los principales documentos internacionales relativos a la protección del patrimonio, principalmente de obras de ingeniería: cartas, normas y declaraciones que aportan juicios acerca de la doctrina sobre la materia a nivel mundial.

La justificación de su puesta en valor contempla los preceptos internacionales, cuyos planteamientos comenzaron a ampliarse a partir de la Carta de Venecia (1964). En ella, la noción de monumento involucra los testimonios de una civilización. Esta carta definió, en principio, el actual concepto de patrimonio. Otro aporte muy relevante que introdujo fue el otorgar valor testimonial no solo a los monumentos arquitectónicos, sino también a las obras modestas entre las cuales se puede ubicar a una obra de ingeniería como el Puente de La Almudena, no en tanto estructura modesta -ya que el hecho de ser parte de la trayectoria Qhapaq Ñan le confiere un valor singular-, sino más bien por ser una estructura con tipología diferente. 


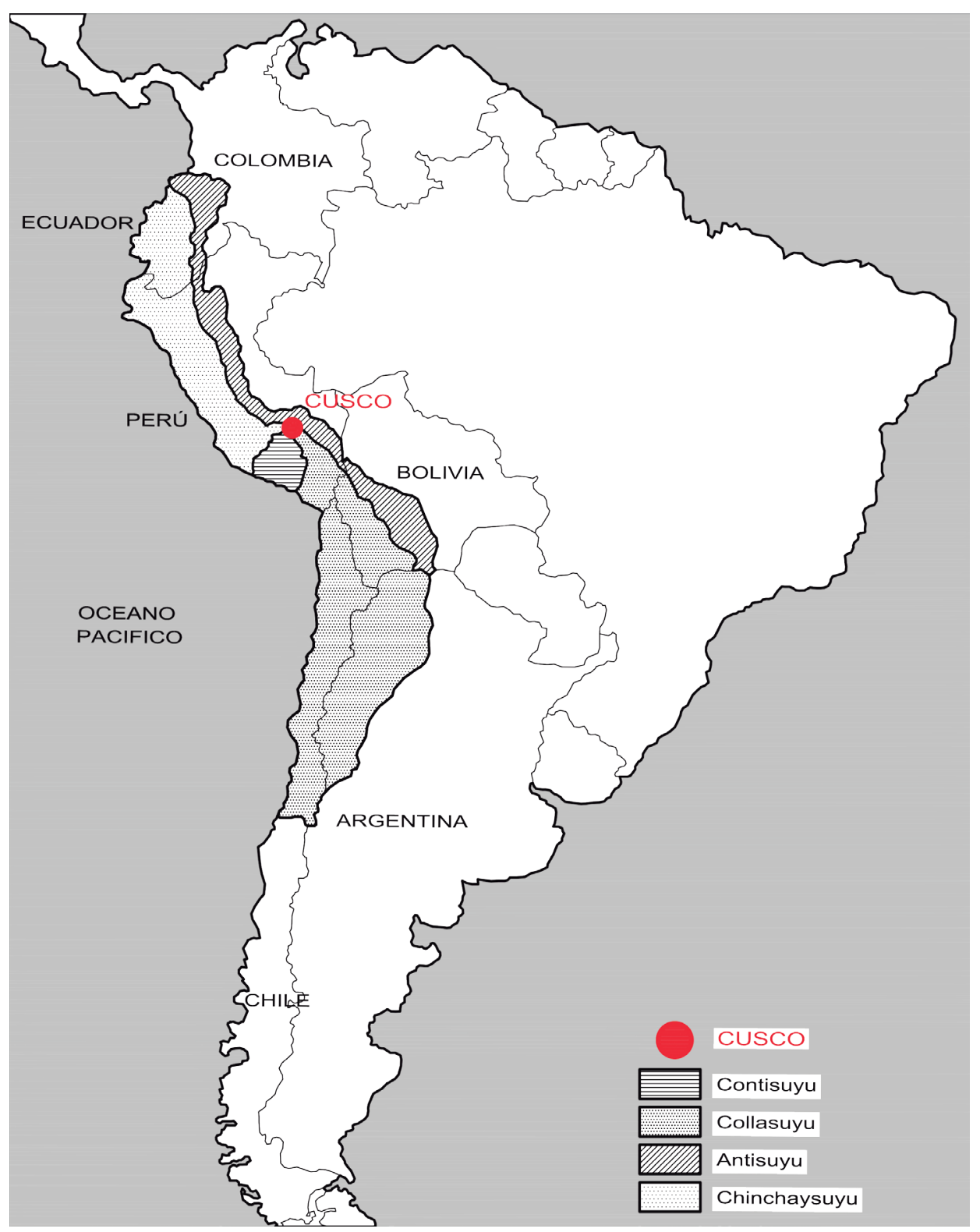

Los resultados de este análisis permitirán mostrar de manera didáctica los bemoles y hallazgos de un proceso de intervención nuevo, donde las discrepancias son un aprendizaje aplicable intervenciones futuras similares.

Como antecedentes geográficos, es necesario mencionar que la ciudad del Cusco o Cuzco se encuentra ubicada en la región suroriental del Perú, a una altura aproximada de $3,350 \mathrm{~m} \mathrm{s.} \mathrm{n.} \mathrm{m.,} \mathrm{y} \mathrm{comprende} \mathrm{principalmente} \mathrm{zonas} \mathrm{andinas} \mathrm{de} \mathrm{la} \mathrm{cordillera} \mathrm{de} \mathrm{los}$ Andes (ver Figura 1). Durante el periodo inca, fue capital del Tahuantinsuyo, una vasta nación que floreció en los andes de Sudamérica entre los siglos XV y XVI, hecho que dotó a la ciudad de expresiones arquitectónicas y urbanísticas de gran valía y belleza, lo cual le ha ganado un lugar preferente en la admiración del público peruano e internacional. En el centro histórico de la ciudad se emplazan números monumentos civiles y religiosos conectados a través de sus pétreas calles y extendidas plazas (ver Figura 2),
Figura 1. Mapa de América del Sur con la división administrativa en suyus de los territorios inca. Destaca Cusco, la sacra ciudad capital. En Agua y forma urbana en la América precolombina: el caso del Cusco como centro de poder inca (p. 80), por A. Beltrán Caballero, 2013, Barcelona, España: Universidad Politécnica de Cataluña. 
devenir Vol. 4, N8, JULIO- DICIEMBRE 2017, PP. 11-32 - Estudios | ISSN 2312-7562 I E-ISSN 2616-4949

UNIVERSIDAD NACIONAL DE INGENIERÍA, LIMA

Figura 2. Plano del Centro Histórico del Cusco, en cuyo límite sudoeste se ubica el puente de La Almudena. Elaborado por Y. Guerra sobre la base planimétrica desarrollada en la Oficina Técnica del Centro Histórico (OTCHC), archivo digital de la Gerencia del Centro Histórico de la Municipalidad del Cusco, 2017.

Figura 3. Eje procesional con la distribución de los monumentos religiosos, emblemáticas plazas y plazoletas más importantes de la ciudad. Plano elaborado en la OTCHC, archivo digital de la Gerencia del Centro Histórico de la Municipalidad del Cusco, 2005.
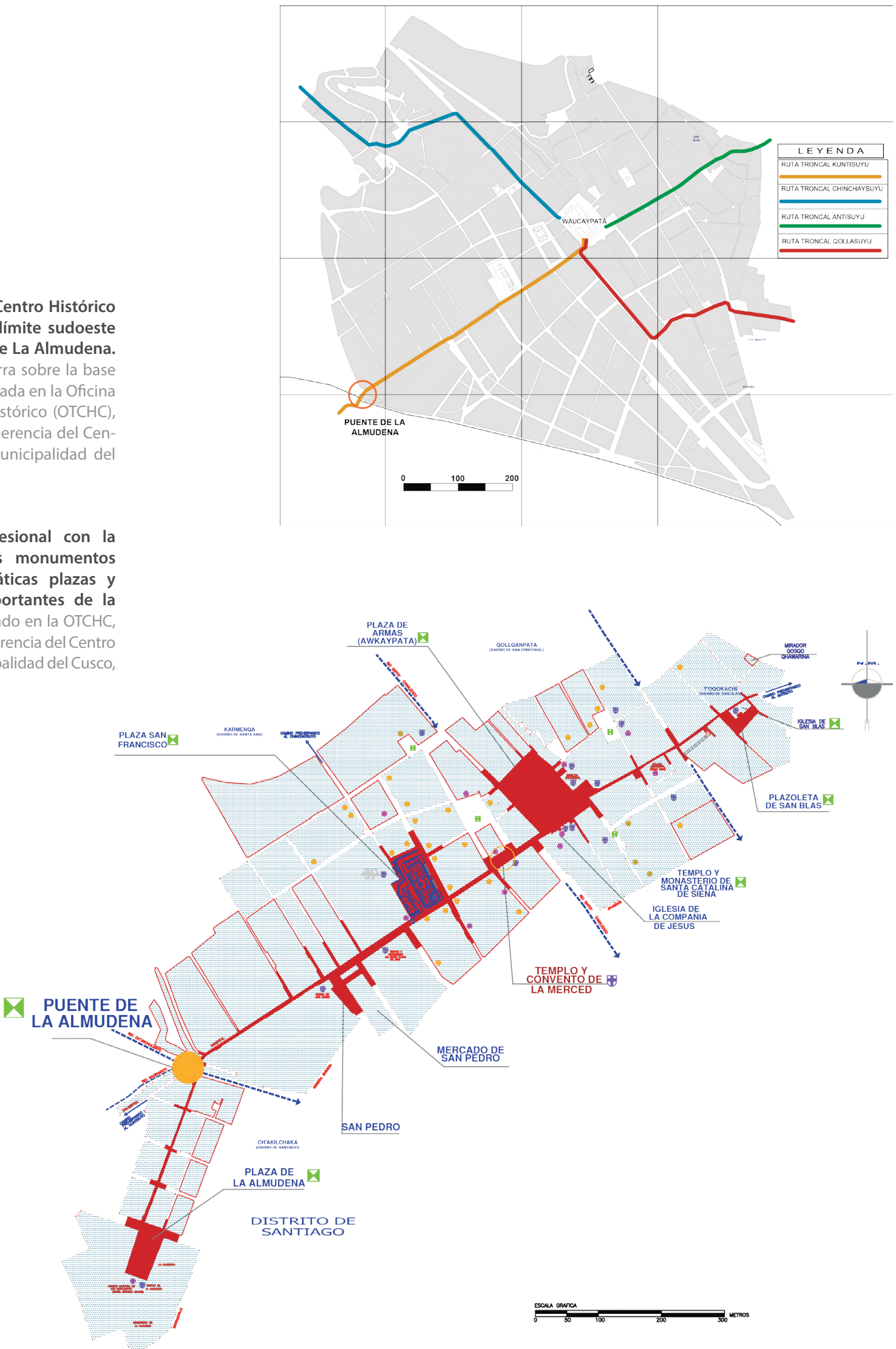

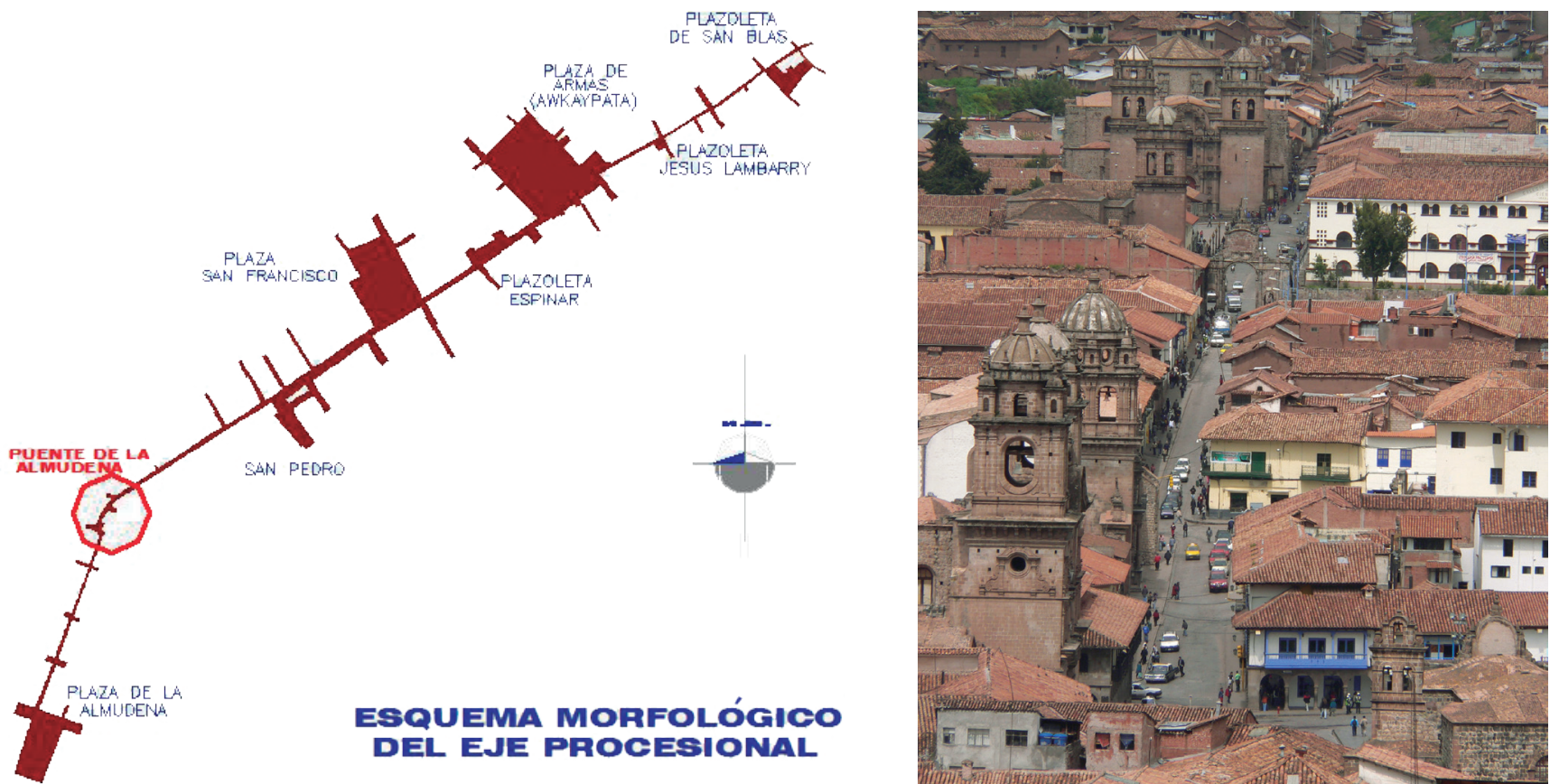

así como su único y peculiar puente original, importante fragmento del Qhapaq Ñan hacia el Kuntisuyu, cuya proyección genera el límite medio entre el hanan y el hurin de la ciudad inca. El nombre del Puente de La Almudena se debe a que es el elemento que posibilita la continuidad de la vía o eje procesional (ver Figuras 3, 4 y 5), un eje trascendental en la virreinal ciudad del Cusco, pues allí se encuentran los principales monumentos religiosos, desde la parroquia de San Blas, al Este de la ciudad, hasta el templo y convento de La Almudena, al Oeste de la ciudad.

Con relación al reconocimiento previo llevado a cabo como primera fase del proyecto, cabe mencionar que el Puente de La Almudena se encuentra ubicado al Noroeste de la ciudad del Cusco, dentro de los límites del Centro Histórico (ver Figuras 6 y 7), en el límite del Cercado del Cusco y el distrito de Santiago. Conecta la calle Hospital y la calle Almudena sobre la hoy conocida Av. Del Ejército, que canalizó el antiguo río Chunchullmayo.

Un resumen de los datos cuantitativos extraídos del primer capítulo del expediente técnico del proyecto Qhapaq Ñan detalla los porcentajes de filiación cultural encontrados (Proyecto Qhapaq Ñan, 2003):

- Filiación cultural según la evidencia material:

- Periodo preinca: $1 \%$ de evidencia material

- Periodo inca: 9\%

- Periodo virreinal: $50 \%$

- Periodo republicano: $20 \%$

- Periodo contemporáneo: $20 \%$

- Intervenciones realizadas:

- Ampliación, 1925

• Restauración, 2003-2006
Figura 4. En el eje procesional no solo coinciden dos caminos del Qhapaq Ñan, sino que también cuenta con alto valor simbólico, por su intensa cultura viva. Plano elaborado en la OTCHC, archivo digital de la Gerencia del Centro Histórico de la Municipalidad del Cusco, 2005.

Figura 5. Eje procesional y los principales monumentos religiosos. Fototeca personal del Arq. Fernando Seminario, 2005. 
devenir Vol. 4, N8, JULIO-DICIEMBRE 2017, PP. 11-32 - EstudIOS | ISSN 2312-7562 I E-ISSN 2616-4949

UNIVERSIDAD NACIONAL DE INGENIERÍA, LIMA

Figura 6. Ubicación del Puente de La Almudena dentro de la delimitación oficial del Centro Histórico del Cusco y su área de amortiguamiento. Plano elaborado por Oficina Técnica del Centro Histórico (OTCHC), Archivo de la Gerencia del Centro Histórico de la Municipalidad del Cusco, 2005.

Figura 7. Actual configuración urbana donde confluyen importantes arterias del Cusco. Recuperado de Google Earth, 2017.
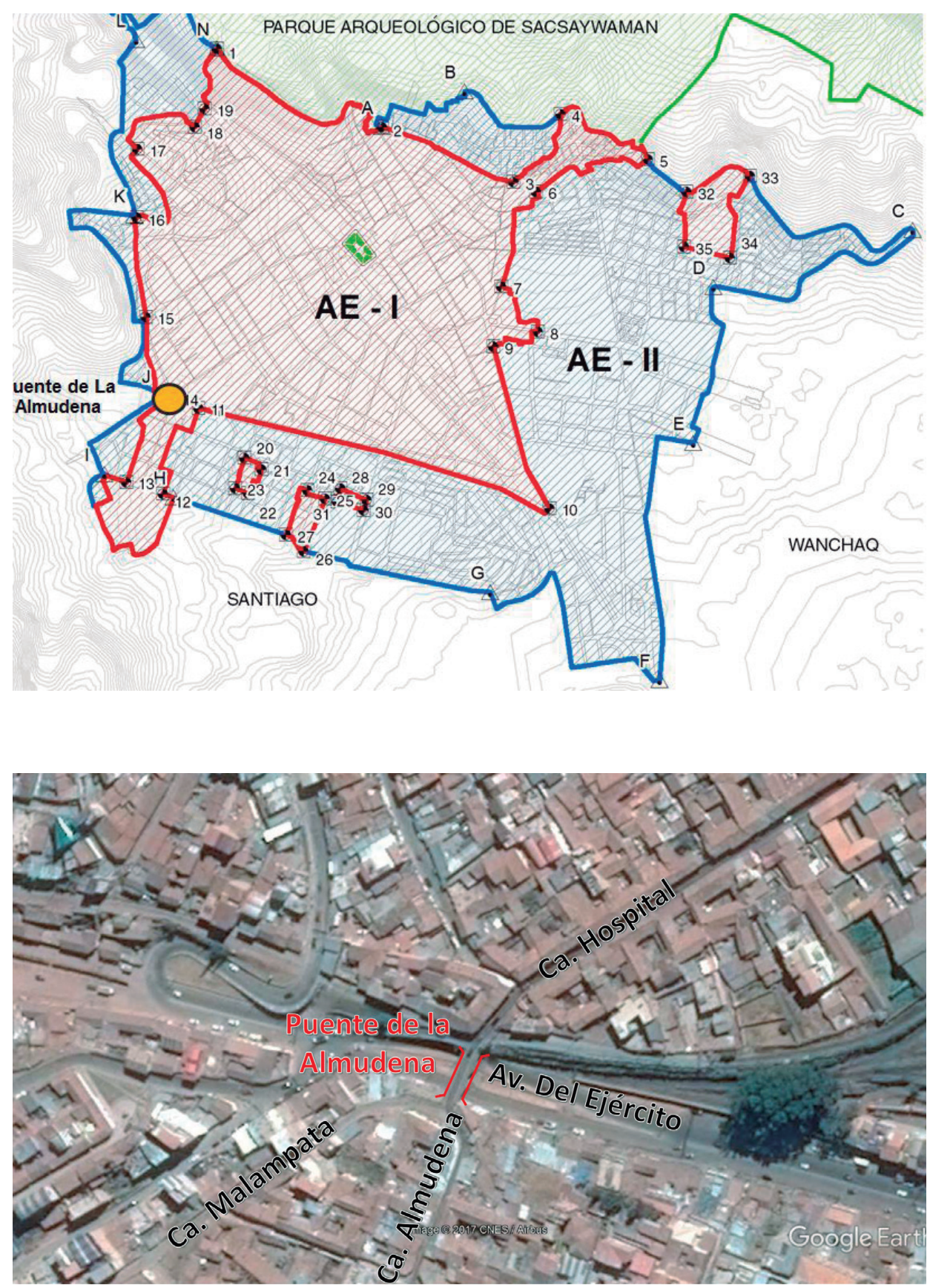

- Área construida: $280.00 \mathrm{~m}^{2}$

- Área libre involucrada en el sector: 1,200.00 m²

- Área de intervención en 2004: 750.00 m²

- Fecha de inicio de obra: 1 de mayo de 2003

- Presupuesto por cada año de intervención:

• 2003, 2004: S/.650,000.00

. 2005: S/. 97,500.00 


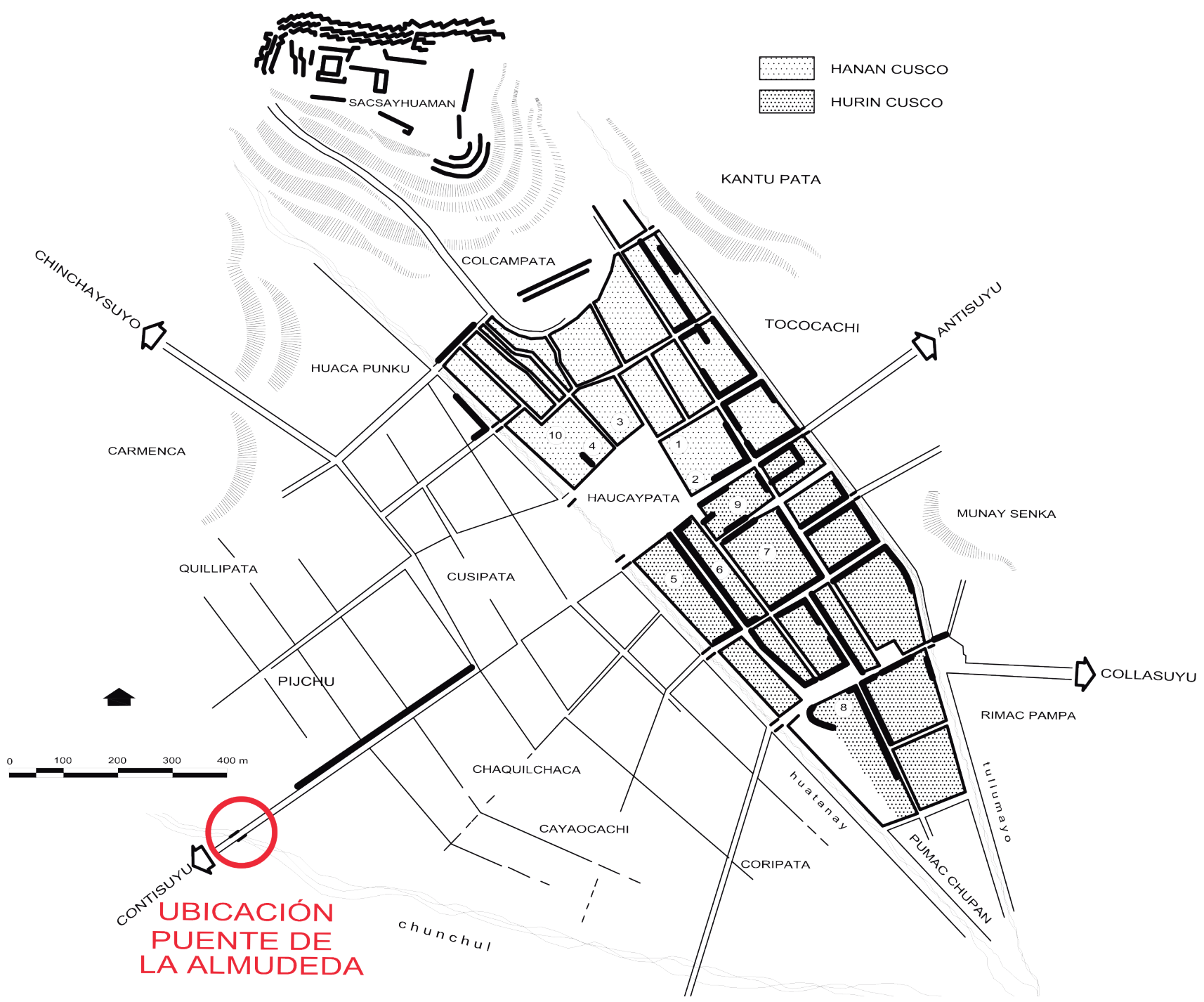

Con relación al valor histórico del puente, es posible afirmar que su importancia data de la época inca, pues forma parte del camino hacia el Kuntisuyu. La historiadora María Rostworowski (2004) refiere que al establecerse los quechuas en esa región el primer gobernante, Manco Cápac, organizó el Cusco y lo dividió en cuatro barrios: Quinti Cancha, Chumbi Cancha, Sayri Cancha y Yarámbuy Cancha. Conforme pasó el tiempo y el asentamiento tomó mayor importancia respecto a otros pueblos, se implantó una nueva división, nuevamente en cuatro sectores, opuestos y complementarios: hanan o hurin (arriba, abajo), e icho y allauca (izquierda, derecha). El Puente de La Almudena formaba parte del camino hacia el Kuntisuyu, como se muestra en la Figura 8, cuya ruta coincide con el eje procesional. El camino al Kuntisuyu se inicia en la Plaza de Armas, delante del actual Paraninfo Universitario, y por las calles Mantas y Marqués, plaza San Francisco, calle Santa Clara, y continúa por el costado derecho del Templo de San Pedro, para seguir por la calle Hospital, pasar por el Puente de La Almudena y proseguir por las calles Malampata, Puquín y Ccorca, donde esta vía se bifurca en dos, a la derecha hacia Chumbivilcas y a la izquierda rumbo a Paruro. Ambas rutas luego coincidirían para llegar a la costa (Catalán Santos, 2004).
Figura 8. Mapa de la ciudad nobiliaria del Cusco de los incas, los principales recintos de factura tahuantinsuyana y la división urbana entre el hanan y el hurin. En Arquitectura inka (p. 48), por G. Gaspirina y L. Margolies, 1977, Caracas, Venezuela: Centro de Investigaciones Históricas y Estéticas, Facultad de Arquitectura y Urbanismo, Universidad Central de Venezuela. 
devenir Vol. 4, N8, JULIO-DICIEMBRE 2017, PP. 11-32 - EstudIOS | ISSN 2312-7562 I E-ISSN 2616-4949

UNIVERSIDAD NACIONAL DE INGENIERÍA, LIMA

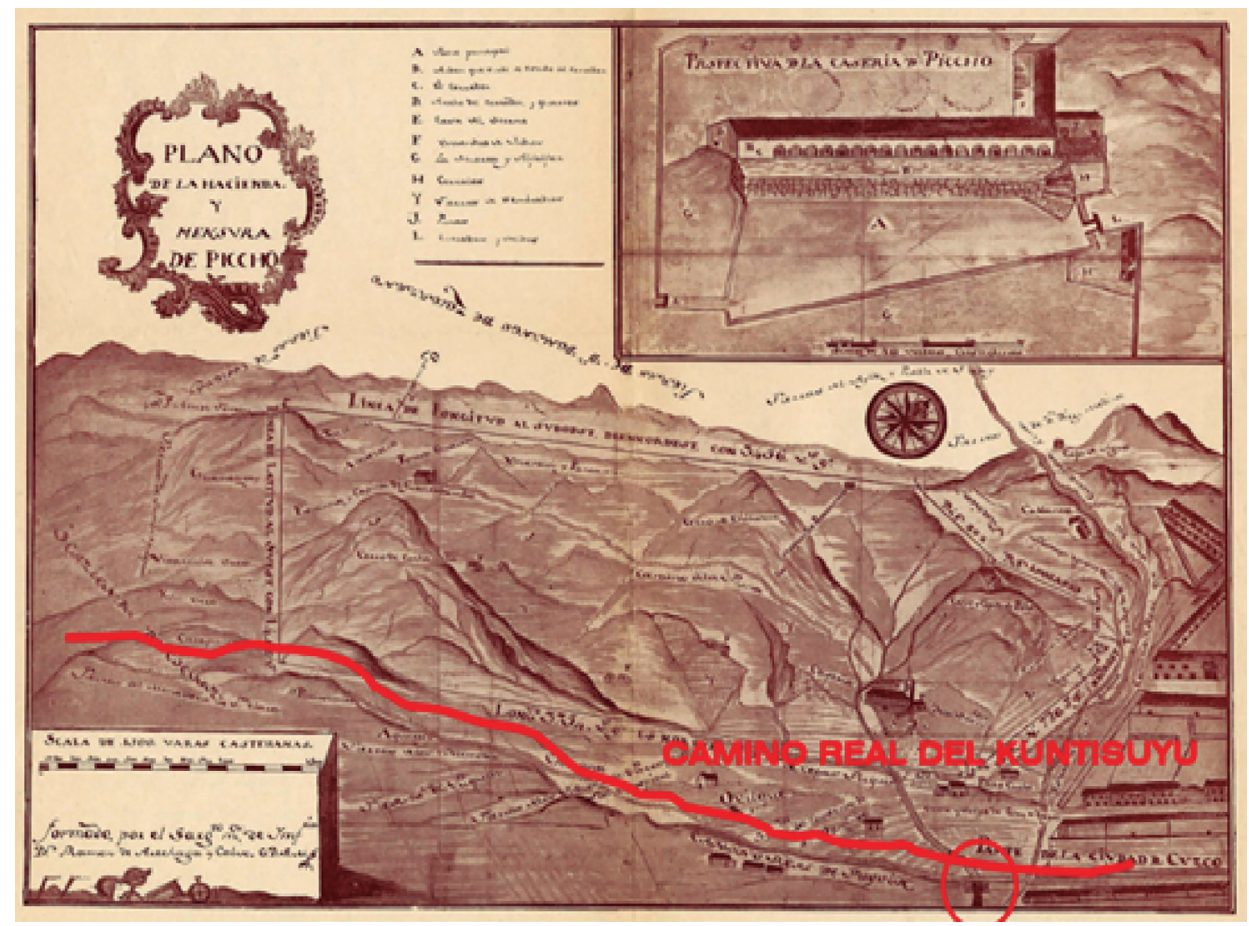

Figura 9. Puente ubicado en el camino del Kuntisuyu. En Informe Anual del Área de Investigación del proyecto Qhapaq Ñan (p. 12), por D. Amado Gonzales (Coord.), 2003, Cusco, Perú: Instituto Nacional de Cultura.
En el plano histórico (ver Figura 9), recopilado por Pablo Macera, cuyas copias figuran en el área de investigación del proyecto Qhapaq Ñan, se aprecia el camino troncal al Kuntisuyu, allí consignado como Camino Real de Puquín, con lo cual se verifica la representación de este puente hacia la salida de la ciudad del Cusco.

Es pertinente referirse nuevamente al expediente técnico del proyecto de intervención, en cuyo capítulo dedicado a los antecedentes históricos se incluye una interesante cita sobre la construcción del puente, encontrada en el artículo de Ángel Carreño "Felonia de Don Pacorro Tijerolin", en el que se menciona que el Corregidor Polo de Ondegardo fue quien dispuso la construcción del puente:

Algunos años después que el conquistador don Francisco Pizarro hizo a sus con nacionales el reparto de solares en la ciudad del Qosqo, llegó el Corregidor Licenciado Polo de Ondegardo, quien fundó las parroquias Ilamadas la Matriz, San Blas, San Cristóbal, Belén, Santa Ana, Santiago y San Miguel... Hizo construir sobre el riachuelo llamado "Chunchullmayo" los puentes de la parroquia de Belén, Santiago y San Miguel, haciendo colocar una cruz en cada puente. Además, hizo construir el puente que mucho después fue llamado por el pueblo "puente de la Almudena", por alusión al Convento y Hospital que fundaron los frailes Betlemitas... (1987, p. 88)

Es probable que el Puente de La Almudena, por su configuración virreinal, haya sido construido en 1559. Hacia el año 1643 el Padre Gaspar de Villagra, cura de la parroquia de Santa Ana, manda a elaborar un plano de su parroquia y del Hospital de los Naturales, el plano más antiguo que se tiene del Cusco, en el cual está representado el puente de La Almudena (ver Figura 10). Existe otra imagen del periodo virreinal en el que se aprecia el puente de La Almudena, así como los paralelos puentes de Santiago y Belén, todos de apariencia similar (ver Figura 11).

En la época de la República tuvo lugar el crecimiento urbano del otro lado del puente, con lo que se consolidó el equipamiento existente, así como el Santuario de los Betle- 


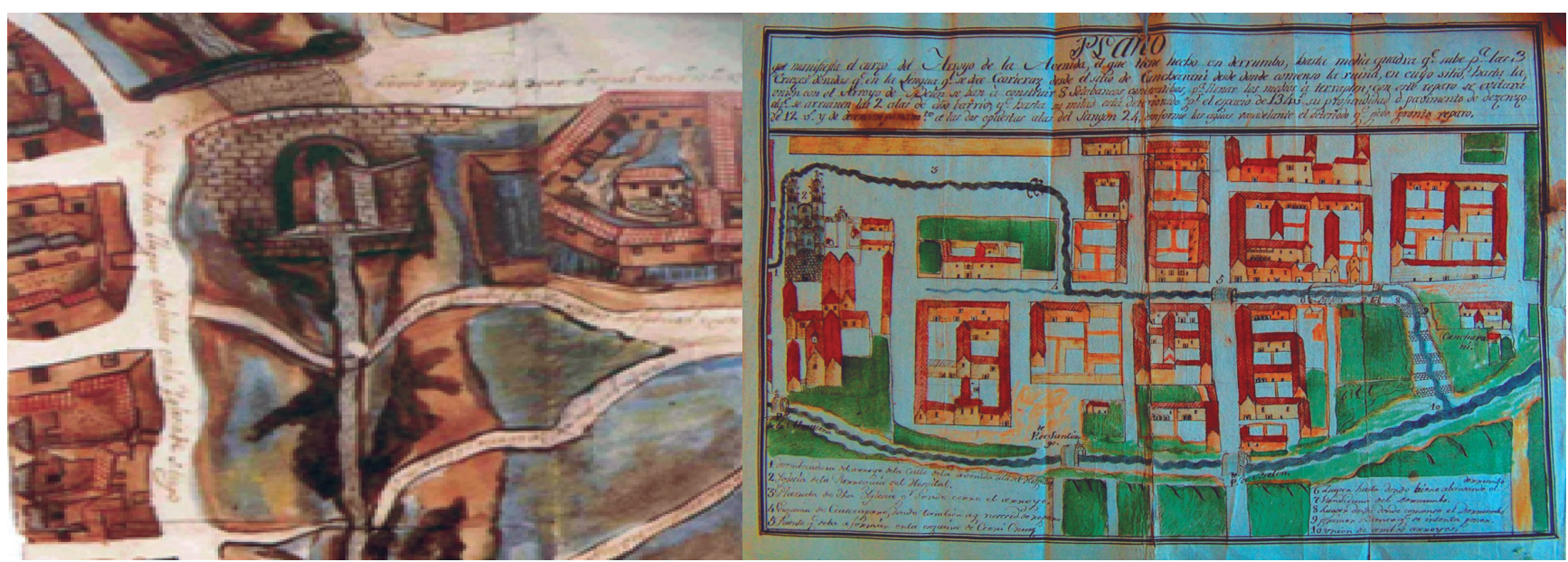

mitas, el Hospital General y el Cementerio General, hoy llamado Cementerio General de La Almudena. Ello requirió que el puente reciba mantenimiento y reparación periódica.

En 1933, durante la gestión del coronel Mendiburu, se realizó la reparación del puente mediante trabajos de reforzamiento de los muros portantes de piedra. Al año siguiente, en 1934, con motivo de la conmemoración los 400 años de fundación española de la ciudad del Cusco, con apoyo de la empresa de ferrocarriles Peruvian Corporation, se reconstruyó puente con un estilo neocolonial (Proyecto Qhapaq Ñan, 2003).

Con la llegada de vehículos motorizados en la primera mitad del siglo XX, surgió la necesidad de reforzar la estructura y ampliar la sección de la calzada del Puente de La Almudena, para lo que se utilizaron nuevos materiales, como el acero y el cemento. También se incorporaron barandas prefabricadas de concreto armado, que permanecerían hasta antes de la última intervención.

Entre los años 2003 y 2006 se realizó la restauración de este puente. El presente artículo aborda este proceso de intervención, que supone un ejemplo valioso de interrelación de diversos actores estatales y privados, gestión de recursos financieros, coordinación y coincidencia de voluntades políticas, y otras acciones colaterales que enriquecen el análisis del ejercicio teórico en su crítica arquitectónica, como refiere Montaner (2002) al referirse a la valoración estética y social.

Con relación a los conceptos restaurativos aplicados en el momento de la intervención, es necesario mencionar que el carácter monumentalista de las prácticas restaurativas que se llevaron a cabo en la ciudad en las tres últimas décadas del siglo XX instauró en la memoria de los ciudadanos, autoridades y profesionales entendidos en el tema la idea de que solo algunos edificios merecían intervenciones de recuperación. Así, la ciudad del Cusco fue testigo de prácticas absolutamente irreversibles, como la demolición de austeras estructuras de adobe que ocasionaron la pérdida de muchas tipologías barriales del patrimonio civil doméstico (Estrada Iberico, 1995). El puente tampoco fue ajeno a la poca valoración patrimonial: en el momento de su recuperación, no era considerado parte de los monumentos más resaltantes de la ciudad.

A finales del s. XX existía un "consciente" carácter monumentalista, obsesionado por recuperar el interior de la ciudad histórica considerando solo arquitecturas resaltantes. No se entendía al patrimonio en su integridad contextual, como parte de un proceso de transformación histórica.
Figura 10. Fragmento del plano más antiguo del Cusco, 1643. En El plano más antiguo del Cusco. Dos parroquias de la ciudad visitadas en 1643 [afiche], por el Instituto Nacional de Cultura, 1996, Cusco, Perú.

Figura 11. Plano de la parroquia de San Pedro en 1789, donde aparecen los puentes de La Almudena, Santiago y Belén, morfológicamente similares. En Archivo Departamental Cusco. Inventario de libros Manuscritos y fotocopias. Documento $N^{\circ} 15$. Expediente que trata sobre la composición del Sanjon de Cori-Cruz [manuscrito roto] (f. 73), s/f, Cusco, Perú. 


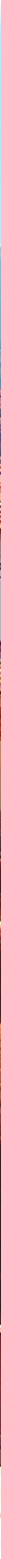

Figuras 12. Imagen urbana del puente de La Almudena, año 2002. Archivo personal M. Landa, 2002.
Con este concepto segregado se dio inicio al siglo XXI, cuando ya se había desatado una secuencia de continuos deterioros, principalmente a nivel de los barrios tradicionales. Durante los primeros tres años tuvieron lugar algunas prácticas nacionales e internacionales que volcaron la mirada sobre el patrimonio que completaba el paisaje cultural. Uno de estos ejemplos fue la intervención realizada en el Centro Histórico de Lima, perfectamente referida por Rodríguez Larraín Echecopar en 2014, en el artículo titulado "Intervenciones en el Centro Histórico de Lima a Partir de su Declaratoria como Patrimonio Cultural de la Humanidad".

Los políticos de entonces empezaron a valorar positivamente las actuaciones patrimoniales cuando, por iniciativa de las instituciones competentes y la ejecución de planes de recuperación del Centro Histórico en las áreas urbanas que circundan al Puente de La Almudena, se rescataron espacios públicos. Un caso palpable fue el del Barrio de San Pedro, que involucró la calle Hospital, que conecta dicho foco comercial con el Puente de La Almudena, conexión con el distrito de Santiago, hecho coronado además gracias a la mediatización del Qhapaq Ñan, el cual ya empieza a ocupar titulares y suscitar interés popular.

Dentro de este recuento, no es posible dejar de mencionar las inducciones en las que aún en los años 90 la Organización de las Naciones Unidas para la Educación, Ciencia y Cultura (UNESCO), y el Consejo Internacional de Monumentos y Sitios (ICOMOS) dieron primacía a la temática en las reuniones disciplinares en el mundo, junto a entidades internacionales como The International Committee for the Conservation of the 

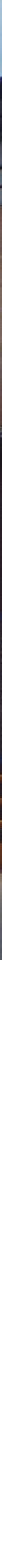

Industrial Heritage. Luego de un largo recorrido, la herencia industrial y las obras de ingeniería dejarían de considerarse como conjunto de meras construcciones funcionales, "sin antigüedad", y tomarían valor patrimonial.

\section{Pero, ¿cómo interpretar el proyecto restaurativo desarrollado entre 2003 y 2006?}

El análisis de esta restauración ha brindado información útil para el análisis de las virtudes y defectos de este proyecto de recuperación patrimonial. Con esta información es posible establecer la conceptualización de esta intervención, a partir de ciertos aspectos clave:

En primer término, el valor histórico de este puente, el último construido con la tecnología virreinal de cal y canto existente en la ciudad de Cusco. A lo largo de la actual avenida Del Ejército, en lo que era la trayectoria del río Chakilchaca, existían otros puentes de piedra, los cuales fueron remplazados por puentes de concreto armado.

En el Puente de La Almudena se evidencian igualmente varios periodos de la historia del Cusco. Durante la ejecución de las obras se puso especial énfasis en mostrar todas las etapas de intervención en este sector con un sentido escrupuloso de conservación, de acuerdo a lo planteado en la Carta de Atenas (1931).
Figuras 13. Cambio de la imagen urbana de La Almudena, año 2017. Archivo personal M. Landa, 2017.

Figuras 14. Ícono establecido en el proyecto de restauración y utilizado en la señalética pública, el cual refleja la solución arquitectónica. En Expediente técnico del Proyecto de Restauración y Puesta en Valor de Puente de La Almudena (p. 1), por Proyecto Qhapaq Ñan, 2003. Archivo documental del proyecto Qhapaq Ñan, Dirección Desconcentrada de Cultura del Cusco, Perú. 
devenir Vol. 4, N8, JULIO- DICIEMBRE 2017, PP. 11-32 - EstudIOS | ISSN 2312-7562 I E-ISSN 2616-4949

ETAPAS DEL PROCESO DE RESTAURACIÓN

\begin{tabular}{l} 
Etapa Pre-Intervención \\
Generación de proyecto por \\
propuesta de demolición \\
Autorización de proyecto \\
mediante comisión califi- \\
cadora \\
Respaldo político a la inter- \\
vención \\
\hline Declaratoria del puente \\
como Patrimonio Cultural de \\
la Nación \\
Autorización mediante \\
Comisión Calificadora \\
\hline Emisor de alerta ante posible \\
demolición \\
Elaboración de propuesta \\
Obtención de recursos finan- \\
cieros del MEF \\
Compromiso financiero \\
Seguimiento a gestión de \\
aprobación
\end{tabular}

\section{Etapa de Intervención \\ Expropiación de inmuebles colindates ilegales \\ Muros de contención colin- dantes \\ Pavimentación de vía colindante}

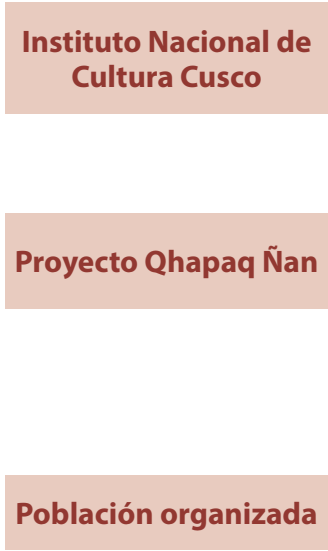

\section{colindante}

Supervisión de monitoreo arqueológico

Supervisión de intervención patrimonial

\section{Ejecución del proyecto}

Ejecución recursos financieros

Monitoreo arqueológico

Registro de ejecución

\section{Apoyo en sesión de áreas} colindantes temporales

\section{Etapa Pos-Intervención}

Culminación de vías transversales

Señalización peatonal

Mantenimiento y limpieza del sector

\section{Monitoreo por Parque de}

Valle de Cusco

Aprobación de PIP para

Plazoleta inferior del sector

Tabla 1. Agentes involucrados en el proceso de restauración.

Elaborado por M. Landa, 2017.

En segundo lugar, la funcionalidad del puente resulta también crucial. Frente a la necesidad de mejorar el intenso flujo vehicular de la avenida Del Ejército, por la parte inferior se da apertura a dos fenestraciones laterales que permiten conectar el centro histórico de la ciudad con los valles del sector oeste.

El Puente de La Almudena tiene carácter patrimonial no solo por el valor de la estructura de mampostería, sino por su ubicación en tramo troncal del Kuntisuyu, que comunicaba el Hawkaypata' con la costa del Perú. Es parte de la red de caminos incas, de su integralidad territorial. Este proyecto se inició en un periodo en el que simultáneamente se empieza recién a dar a conocer en el Perú el valor de la red de caminos Qhapaq Ñan. Es por esta trayectoria que el pescado llegaba fresco desde la costa para el consumo de los incas

Otro aspecto relevante del proyecto de restauración es la naturaleza interdisciplinaria del trabajo de recuperación de una evidencia patrimonial. En la ejecución de estos proyectos participaron arquitectos, arqueólogos, ingenieros civiles y antropólogos, los cuales asumieron responsabilidades de acuerdo a su formación académica, de acuerdo a lo señalado en la Carta de Atenas (1931) (INC, 2007). 


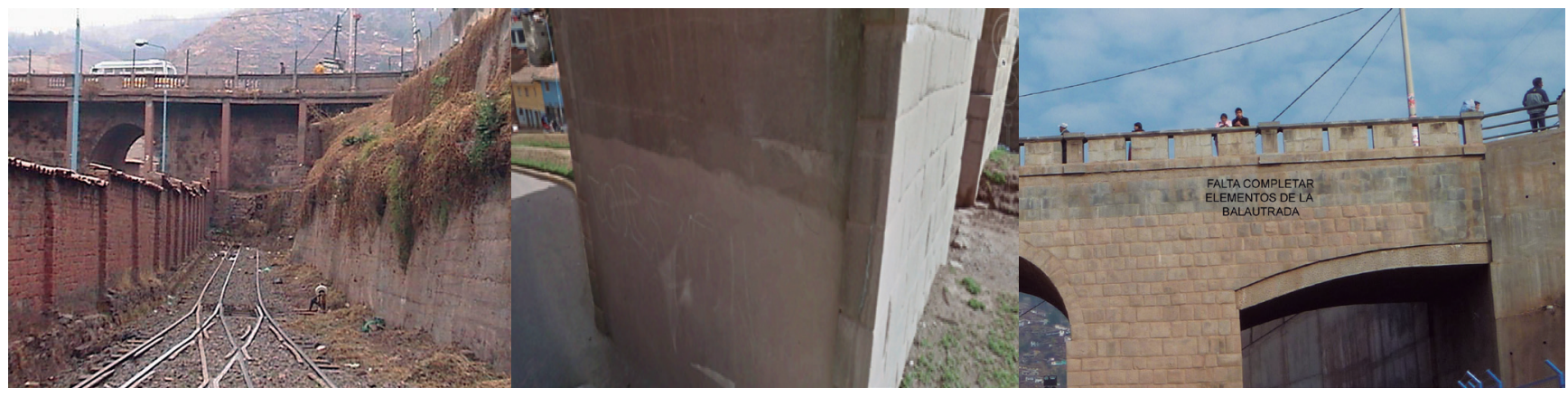

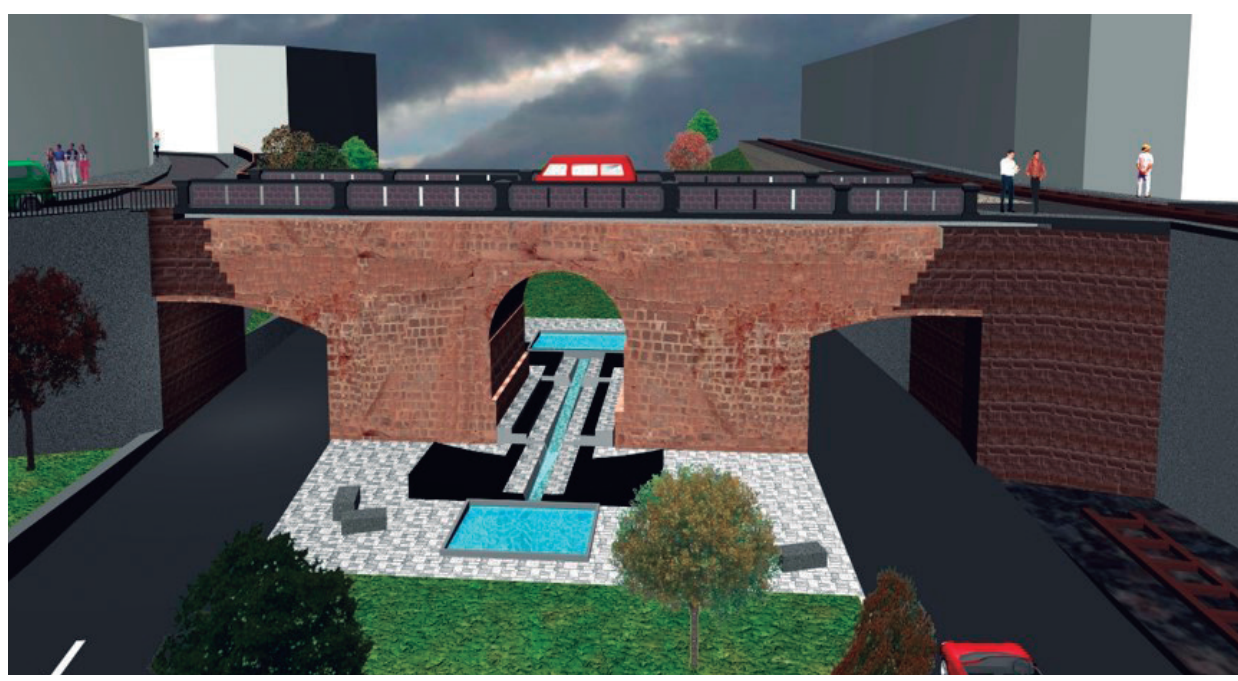

Sobre el proceso de recuperación, es necesario mencionar que el proyecto de intervención se planteó a raíz de una iniciativa del entonces alcalde del Cusco, el ingeniero Carlos Valencia, quien realizó acciones para mejorar el entorno urbano de la avenida Del Ejército, como el traslado de todos los comerciantes asentados sobre las rieles de esta avenida, en el entonces sector conocido como El Contrabando. Esta recuperación permitió mostrar el entorno urbano del sector, incluyendo el puente. Para dar continuidad a esta recuperación urbana se planteó la demolición del puente y la construcción de uno nuevo, con estructuras de concreto armado, propuesta que se presentó a la comunidad cusqueña (Figura 14).

Es en ese momento que desde el recientemente iniciado Proyecto Qhapaq Ñan, del entonces INC, se indicó que ese puente no debería ser demolido, por su valor patrimonial. Así, se encargó la responsabilidad de elaborar el proyecto de recuperación y puesta en valor del puente al personal profesional del mismo proyecto. La propuesta final de intervención recibió la aprobación de la Comisión Externa Calificadora de Proyectos del INC, luego de un periodo de dos años, durante el que se elaboró el diagnóstico y registro de información existente, así como la propuesta de intervención.

La instancia encargada de la ejecución fue el Proyecto Qhapaq Ñan; además, se contó con una activa participación la autoridad municipal, pues alrededor de la infraestructura era necesario realizar acciones de retiro de viviendas ilegalmente adosadas a la mampostería y ubicadas sobre la vía pública. El municipio fue también responsable de
Figura 15. Fachada sur del puente antes de la intervención. Se puede apreciar el área ocupada por las vías ferroviarias, junto con la mampostería del puente. Fotografía por M. Landa, 2002.

Figura 16. Intradós inconclusos. Archivo fotográfico personal Y. Guerra, 2017.

Figura 17. Balaustrada existente incompleta. Archivo personal Y. Guerra, 2017.

Figura 18. Recreación 3D de la propuesta de la base del puente. En EXpediente técnico del Proyecto de Restauración y Puesta en Valor del Puente de La Almudena (p. 46), por Proyecto Qhapaq Ñan, 2003. Archivo documental del proyecto Qhapaq Ñan, Dirección Desconcentrada de Cultura del Cusco, Perú. 
devenir Vol. 4, N8, JULIO - DICIEMBRE 2017, PP. 11-32 - EstUdIOS | ISSN 2312-7562 I E-ISSN 2616-4949

UNIVERSIDAD NACIONAL DE INGENIERÍ, LIMA

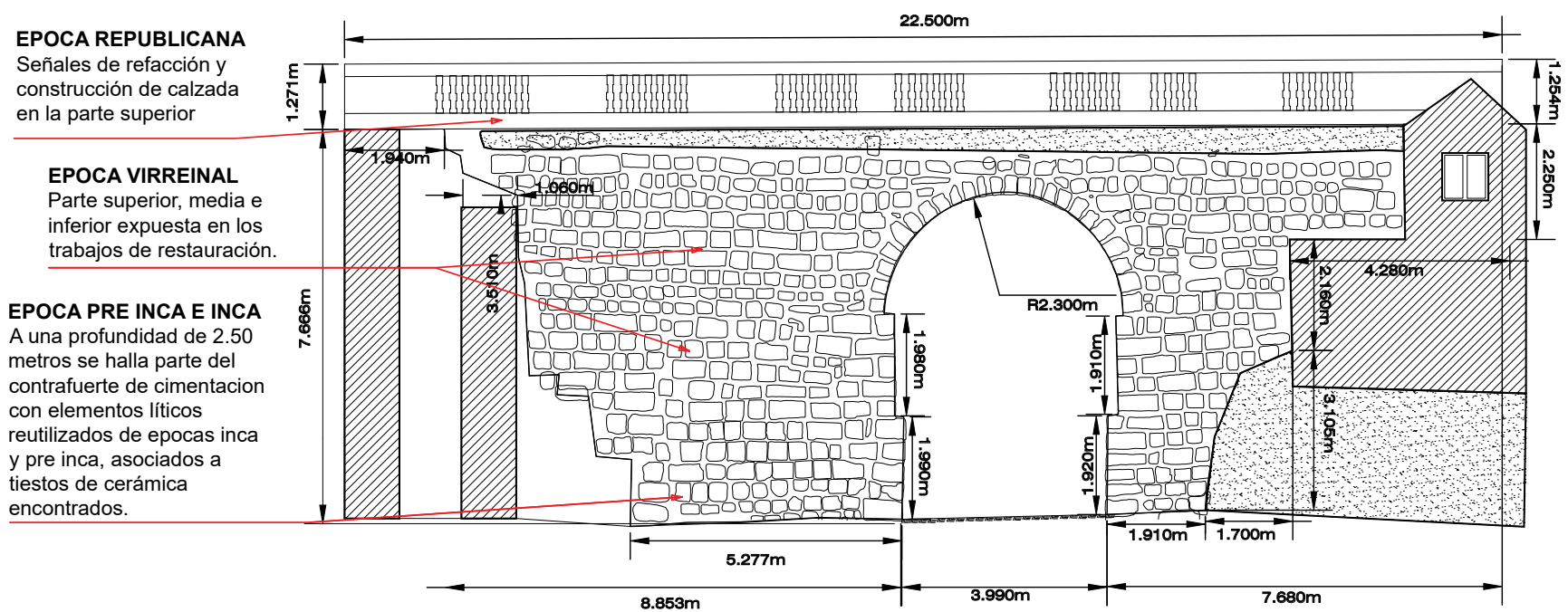

Figura 20. Periodos culturales del puente. En Expediente técnico del Proyecto de Restauración y Puesta en Valor del Puente de La Almudena (p. 80), por proyecto Qhapaq Ñan, 2003. Archivo documental del proyecto Qhapaq Ñan, Dirección Desconcentrada de Cultura del Cusco, Perú.

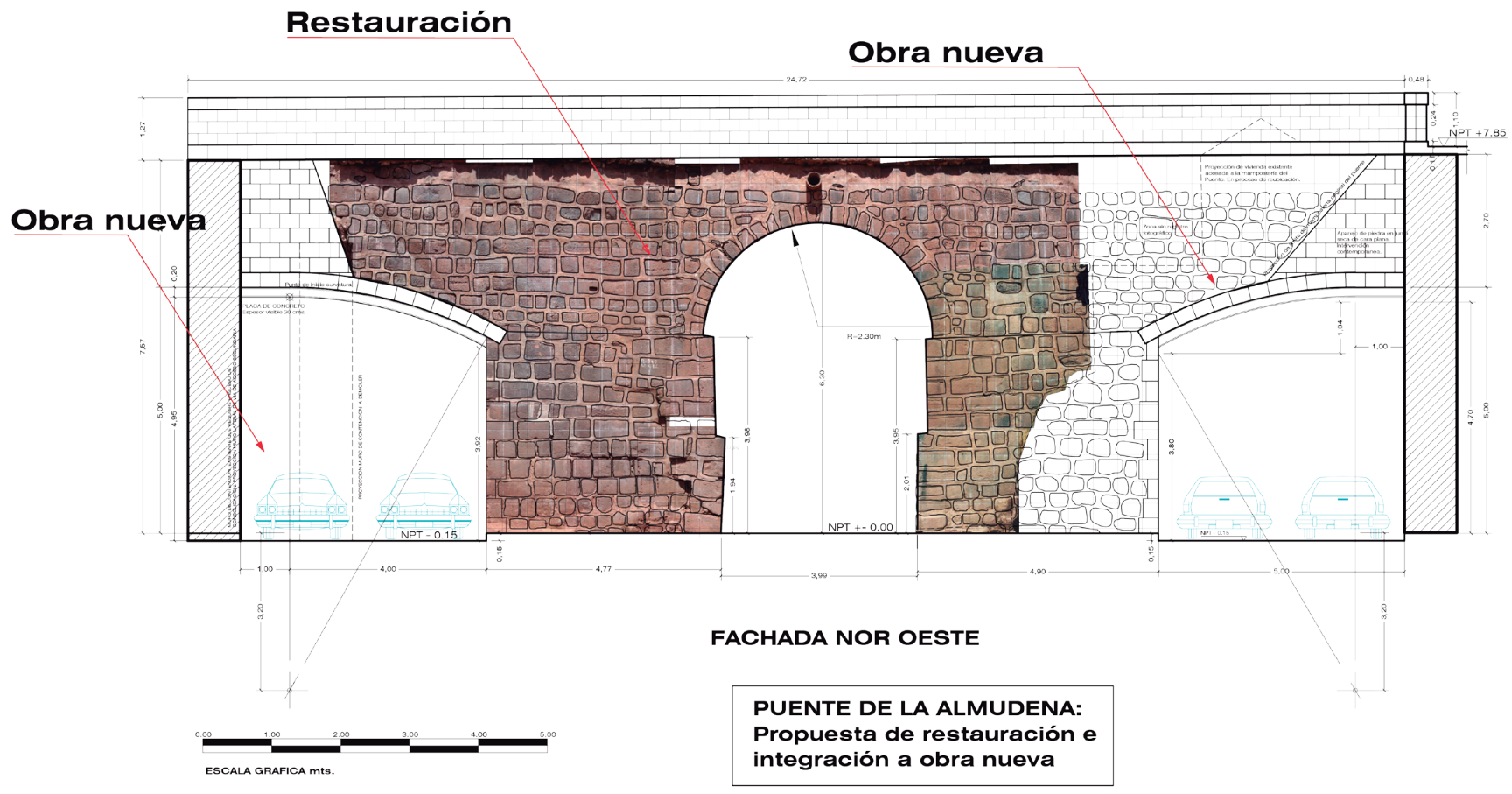

Figura 21. Proporción de etapa histórica recuperada. Restauración y obra nueva. En Investigación Arqueológica del Puente de La Almudena (p. 12), por E. Catalán Santos, 2004, Cusco, Perú: Proyecto Qhapaq Ñan. 
Tabla 2. Recuperación porcentual de fases constructivas históricas

$\begin{array}{lll}\text { Fases históricas constructivas } \quad \% \quad \text { Observaciones } & \% \text {. }\end{array}$

\begin{tabular}{ccc}
\hline Preinca / inca & $0.50 \%$ & $\begin{array}{c}\text { Lo hallado en la cimentación del puente } \\
\text { (reutilización de elementos líticos) }\end{array}$ \\
\hline Virreinal & $55 \%$ & $\begin{array}{c}\text { Mampostería que conformaba la parte } \\
\text { visible del puente }\end{array}$ \\
\hline Republicano & $15 \%$ & $\begin{array}{c}\text { Calzada y columnas implementadas en } \\
\text { las primeras modificaciones }\end{array}$ \\
\hline Contemporáneo (restaurativa) & $25 \%$ & Trabajos de restauración 2004
\end{tabular}

Elaborado por M. Salas [trabajo de investigación del curso de maestría en Gestión y Conservación del Patrimonio Cultural y Centros Históricos, Universidad Nacional San Antonio Abad del Cusco], 2017.

la construcción de muros de contención laterales colindantes que permitirían habilitar el paso de vías vehiculares laterales.

Otra instancia que tuvo también participación continua fue la empresa de ferrocarriles Perú Rail, pues parte del trazo de las líneas férreas había también ocupado un área colindante a la mampostería de los puentes, como se observa en la Figura 15. La intervención impulsó que parte de este trazo sea trasladado, de forma que el área ocupada por Perú Rail sea parte también del proyecto urbano del entorno.

Resulta claro que esta intervención motivó la interacción de agentes involucrados en la recuperación de este puente durante la etapa proyectual y de ejecución, mas no en el proceso de mantenimiento (ver Tabla 1).

Respeto a los recursos financieros gestionados en 2003, se contó inicialmente con un presupuesto aproximado de S/.650,000.00, aprobado por resolución de la Dirección de Cultura de Cusco. Sin embargo, durante el proceso restaurativo, en 2005, luego de un periodo de dos años en elaboración de proyecto y aprobación respectiva, encontrándose el proyecto en plena de ejecución, se exigió que el proyecto sea autorizado por el Ministerio de Economía. Para no paralizar la realización de las obras, se tuvo que gestionar la rápida aprobación de un Perfil de Inversión Pública (PIP) Menor, por un monto menor a S/. 100,000.00, presupuesto que no permitió la conclusión de todas las partidas que contemplaba el expediente técnico, lo cual se hizo evidente después del proceso restaurativo:

1. Tratamiento con revestimiento de piedra de la parte interior de las fenestraciones y de la cara visible de la estructura de concreto armado (ver Figura 16)

2. Revestimiento con piedra de la parte inferior de la balaustrada hacia las fachadas Norte y Sur, fachadas principales (ver Figura 17)

3. Tratamiento del área inferior, intervención que contemplaba una plazoleta en forma ojival (diseño autorizado por la Comisión Calificadora de Proyectos), en la cual se definiría el tránsito peatonal complementado con representación de remembranza de la canalización inca con un recorrido de agua real mediante un canal de muy poca profundidad que conecte dos espejos de agua. Complementa la alegoría una superficie en terrazo 
devenir Vol. 4, N8, JULIO-DICIEMBRE 2017, pp. 11-32 - Estudios | ISSN 2312-7562 | E-ISSN 2616-4949

UNIVERSIDAD NACIONAL DE INGENIERÍA, LIMA

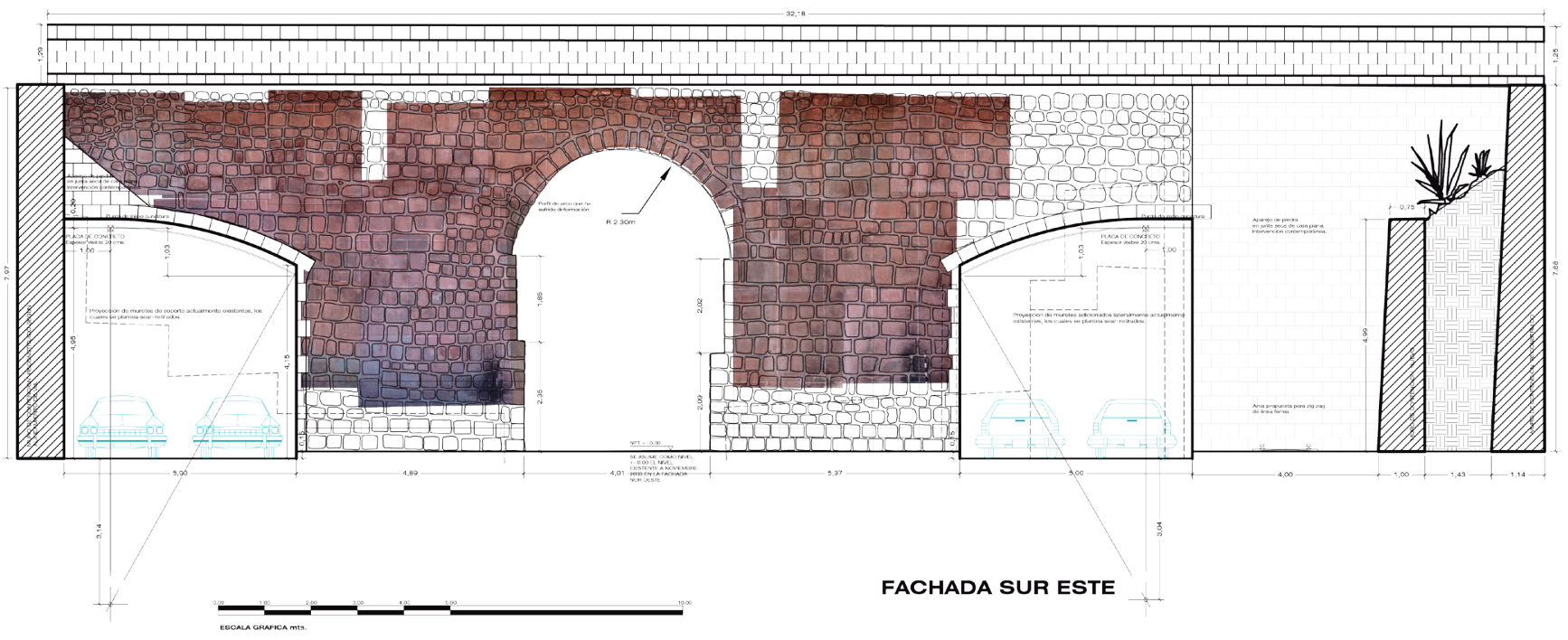

Figura 22. Camino a la fusión de la restauración del bien patrimonial y la obra nueva. Archivo personal M. Landa, 2005. negro, con aspecto de aparente sombra, que simule la profundidad de la canalización subyacente debajo del nivel de piso terminado actual (ver Figuras 18-20).

Durante los trabajos de intervención se pudo constatar que en 1927 se intervino parte del puente. Asimismo, en 1933 se realizó una reparación y el reforzamiento de los muros portantes de piedra. Tras la llegada de los primeros vehículos a la ciudad se amplió la calzada del puente, utilizando acero y cemento, y se incorporaron barandas.

Tras realizar excavaciones arqueológicas en la cimentación del puente, se evidenció más hiladas de piedra reutilizada de época inca y preinca (killke) hasta 2.50 metros de profundidad, para el encauce del río Chunchullmayo hacia el lado Norte. La Tabla 2 expresa las proporciones encontradas en los procesos de intervención.

Los criterios teóricos de la intervención han sido elaborados sobre la base de normativas internacionales de restauro para fines de revitalización, renovación urbana, conservación, y restauración de sitios y centros históricos. Estos conceptos concuerdan con los referidos por Alejandro Novacovsky, que señala objetivos similares: "devolver a un objeto su apariencia o forma perdida, no solo con la idea de conservar la integridad del bien, sino también de revelar su valor cultural y mejorar la legibilidad de su diseño original" (2001, pp. 115-120).

La Carta de Venecia (1964) parece ser el documento de referencia base que se usó en el proyecto y en la obra misma. En primer término, el registro de información histórica es el que brindó las pautas que permitieron entender la evolución geométrica del puente, inclusive desde épocas preincas. Esta evolución permitió identificar la valoración patrimonial de la infraestructura a conservar, a restaurar y a retirar. La carta indica que "la recuperación de un monumento histórico debe mostrar el paso de las diferentes etapas de la historia de ese monumento" (INC, 2007, p. 137). Así, en la ejecución se buscó diferenciar los elementos líticos colocados en época virreinal, los elementos líticos labrados en época inca reutilizados, la balaustrada superior de geometría republicana y otros. La referencia histórica permitió plantear el retiro de una crujía de columnas de concreto armado y una losa de rodadura vehicular superior, adicionadas en los años 1920 a 1925.

Desde una postura tolerante se reconoce que la intervención de reconstrucción del puente fue una acción loable a favor de la ciudad, la cual además ha consolidado un 
devenir Vol. 4, Nº8, JULIO - DIIIEMBRE 2017, PP. 11-32 - ESTUDIOS | ISSN 2312-7562 | E-ISSN 2616-4949

UNIVERSIDAD NACIONAL DE INGENIERÍA, LIMA

Tabla 3. Ficha de crítica conceptual

Variables Referencias (INC, Documentos fundamentales para el patrimonio cultural, 2007, pp. 131-261)

Diálogo antiguo /

contemporáneo

Integración de partes faltantes

Carta de Nizhny Tagil sobre el Patrimonio Industrial, 2003

La reconstrucción debe considerarse como una intervención excepcional que sólo es apropiada si beneficia a la integridad del sitio entero (Carta de Nizhny Tagil sobre el Patrimonio Industrial, 2003).

Reconstrucción parcial o total

Incorporación de obra nueva Reversibilidad

La arquitectura de hoy al construir el patrimonio de mañana debe disponer todos los medios para asegurar una arquitectura contemporánea de alta calidad (Normas de Quito, 1967)

\section{Actuaciones Puente de la Almudena}

Aunque tímidamente, se deja constancia del sello de época o de la fecha de intervención, evitando confusiones entre auténtico e inauténtico.

Reconstrucción total que se aplica para completar un hecho histórico

Ante la necesidad publica de conexión se incorpora una obra nueva de impacto, pero trata de no agredir a la preexistencia. No resalta ni opaca; sin embargo, ese no producir un impacto visual cambia la imagen urbana.

Son mixtas, técnicas nuevas y tradicionales empleadas por personal especializado, además de la utilización de tecnología moderna

La Declaración de Amsterdam expresa que los materiales y técnicas nuevos deben estar ratificados por instituciones específicas.

Las técnicas de conservación o protección deben estar estrictamente vinculadas a la investigación pluridisciplinar científica sobre materiales y tecnologías usadas para la construcción, reparación y/o restauración del patrimonio. (Carta de Cracovia, 2001).
Diferencia entre lo existente, lo nuevo y lo agregado

\section{Equilibrio con el entorno}

Relación con el entorno.

Equilibrio: entre espacios abiertos y cerrados
Las Normas de Quito expresan que el entorno forma parte del monumento que, puesto en valor, revaloriza el bien. Por su parte, la Carta de Brasilia establece la autenticidad del mensaje del edificio a través de relaciones de masa, color y textura entre edificio y contexto
En la intervención no existen modificaciones ambientales, sino una integración armoniosa con el entorno, que posteriormente es alterado por edificaciones privadas fuera de los paramentos establecidos.

\section{Espíritu del lugar} Testimonio

Correspondencia entre objeto material y significado.
La Carta de Brasilia establece que un mensaje es auténtico cuando existe correspondencia entre el objeto material y su significado
La puesta en valor afirma su importancia y significación, y constituye una lección viva de su historia.

\section{Planificación urbana}

\section{Renovación}

Puesta en valor y acción

reflejada sobre el perímetro urbano

\section{Autenticidad}

Aspectos genuinos: espacio/ forma/ textura/ color
La puesta en valor de un bien ejerce una beneficiosa acción reflejada sobre el perímetro urbano (Normas de Quito, 1967)
Revitalización del área anexadas a otras obras de renovación urbana
La renovación de prácticas evolutivas en continuidad cultural como la sustitución de algunos elementos con las técnicas tradicionales, resulta una respuesta auténtica (Carta de Brasilia, 1995).
La autenticidad no se relaciona con la materialidad del puente sino con la expresión de aspectos genuinos, como el espacio, la textura, la forma o el color.
Sello de época

Legibilidad de las diversas intervenciones
Carta de Venecia, deben respetarse las contribuciones de los diferentes periodos por los que atravesó el bien. La Carta de Brasilia recomienda poner de relieve las vicisitudes a las que fue expuesto a lo largo de su historia, sin alterar su carácter ni autenticidad
Tímidamente reconoce las diversas intervenciones, distinguiendo los componentes originales de los añadidos o restaurados.

\section{Reutilización o adecuación}

Uso y Adecuación: admite

función diferente a la original, priorizando el hecho social
Se asigna a los edificios funciones que respondan a necesidades de la vida contemporánea, respeten su carácter y garanticen su supervivencia (Declaración de Amsterdam, 1975).
Por la función y valor utilitario, supera ampliamente la priorización de uso original $y$ hecho social. 
XX, las teorías de conservación eran aplicadas a edificaciones de relevancia histórica y cultural, sin dar cabida a obras de ingeniería, o a las del patrimonio industrial. Hoy en día, esta evidencia de ingeniería, más que lugares para contemplar o preservar, son recursos culturales, sociales, económicos y utilitarios. En ese sentido, el patrimonio ingenieril alude a todo sistema de comunicación y conexión; es de uso permanente y cada vez más transitado. Un puente en un centro histórico involucra a aquellos espacios de la memoria de la producción que aportan sentimientos de identidad.

Este tipo de patrimonio, según la Carta de Nizhny Tangil, "se compone de los restos de la cultura tecnológica que poseen un valor histórico, social, tecnológico, arquitectónico o científico" (Comité Internacional para la Conservación del Patrimonio Industrial [TICCIH] , 2003, p. 1-7), y comprende bienes tangibles (inmuebles de producción, transporte, etc., y muebles, como archivos, mobiliario, maquinarias, herramientas, etc.) e intangibles (marcas culturales: modos de vida, costumbres y tradiciones). Por lo tanto, el patrimonio industrial incluye las evidencias referidas a la existencia de un sitio de producción, infraestructura o transporte, sean estas edificios, herramientas o actividades.

Por su parte, el Documento de Nara (1994) sobre autenticidad plantea que la conservación "comprende todas las operaciones dirigidas a entender una obra, a conocer su historia y su significado y a asegurar la perdurabilidad de los materiales $y$, eventualmente, su restauración y su puesta en valor" (citado en INC, 2007, p. 427). En este sentido, la Carta de Burras ${ }^{2}$ considera los siguientes métodos o procesos de conservación: (1) preservación (operación para retardar el deterioro); (2) mantenimiento (intervención menor para dar continuidad al bien); (3) reconstrucción (acción de recomposición arquitectónica en base a evidencias documentales); (4) restauración (retorno al estado original introduciendo nuevos materiales) y (5) adaptación (inclusión de usos compatibles) (citada en INC, 2007, p. 169).

Entrelazando el análisis minucioso de la experiencia de intervención y la interpretación de los documentos internacionales señalados, utilizando un modelo de análisis presentado en el caso de un patrimonio industrial (Iturria, V., Tuler, S., Ponce, N., \& Sessa, E., 2009, pp. 9-11), se aplica un cuadro de estudio que presenta variables que pueden emplearse como instrumentos que ayudan a evaluar el caso.

\section{Conclusiones}

Las acciones realizadas para la recuperación y puesta en valor del Puente de La Almudena corresponden a una acción de restauración, la cual obtuvo resultados, en buena medida, óptimos, gracias al modelo estructural por el que se optó y a los materiales utilizados, en particular el empleo de concreto para consolidar la labor de reconstrucción y obra nueva. El puente tiene un valor utilitario sin fines de promoción turística - circulación de transeúntes, y tránsito de vehículos pesados, por encima y por debajo del puente-, por lo que el principal beneficiario es el poblador local.

La obra final ha quedado inconclusa por razones de gestión de los recursos financieros del Sistema Nacional de Inversión Pública, tal vez uno de los puntos más importantes que ha ocasionado que la intervención no haya generado un impacto económico en el poblador del entorno inmediato ni el disfrute de un espacio de recreación pasiva, falencia que puede ser revertida con la conclusión de las intervenciones complementarias.

Resulta evidente que las acciones del Proyecto Qhapaq Ñan son de carácter interdisciplinario y la gestión en el momento de la intervención rescata el carácter interinstitucional. Uno de los logros más importantes de la intervención ha sido el esta-

\footnotetext{
2. Carta Internacional para la Conservación y Restauración de Monumentos y Sitios, adoptada por ICOMOS el
} 19 de agosto de 1999 en Burra, Australia. 
blecer pautas para futuras intervenciones: ha estimulado a las autoridades a desarrollar normas legales y directivas institucionales para intervenir en caso de necesidad, ha fomentado la especialización de profesionales, y ha inducido a la participación de los entes locales, en calidad de actores, en temas de protección y conservación patrimonial.

No se puede pretender buscar prácticas similares y acceso a las obras desde casos análogos, planteados como herramientas metodológicas de proyecto acordes a los preceptos nacionales o internacionales, ya que esta intervención constituye una única práctica de este tipo, que, desde diversas perspectivas, constituye una fuente primaria del accionar patrimonial.

Existe una clara necesidad de profundizar las investigaciones en el campo proyectual del patrimonio de obras de ingeniería, especialmente aquellas relacionadas con el camino Qhapaq Ñan, con referencias que enriquezcan la base conceptual. Desde ese punto de vista, se propone plantear la construcción de un marco referencial que, desde el análisis de los preceptos internacionales referidos a la cuestión, permita obtener lineamientos que aporten sustento teórico y metodológico a proyectos de intervención patrimonial similares. Esta investigación debe estar motivada por el rol histórico de la ciudad del Cusco: la integración de territorios en el Ande sudamericano con un centro físico, la Plaza de Armas del Cusco. Del Cusco renace la integración andina, por medio del Puente de La Almudena.

\section{Referencias}

Agencia Española de Cooperación Internacional. (2012). Proyectos Perú 1990-2011. Lima, Perú: ORUS.

Beltrán Caballero, A. (2013). Agua y forma urbana en la América precolombina: el caso del Cusco como centro de poder inca. Barcelona, España: Universidad Politécnica de Cataluña.

Brandi, C. (1972). Cartas italianas del restauro - Instituto de Cultura Italiano. Recuperado de http:// ipce.mcu.es/pdfs/1972_Carta_Restauro_Roma.pdf

Capitel, A. (1988). Metamorfosis de monumentos y teorías de la restauración. Madrid, España: Alianza Editorial.

Carreño, A. (1987). Feledonia de Don Pacorro Tijerolin. En A. Carreño, Tradiciones Cuzqueñas (pp. 87-88). Cusco, Perú: Amauta.

Catalán Santos, E. (2004). Investigación arqueológica Puente de La Almudena (Instituto Nacional de Cultura, Ed.). Cusco, Perú: Proyecto Qhapaq Ñan.

Congreso Internacional del Patrimonio Industrial. (2003). Carta de Nizhny Tagil sobre el patrimonio industrial. En XII Congreso Internacional TICCIH XII - ICOMOS (pp. 1-7). Moscú, Rusia: Comité Internacional para la Conservación del Patrimonio Industrial.

Estrada Iberco, E. (1995). Cercanías y desencuentros: el centro histórico del Cusco. Crónicas Urbanas, (1), 25-30.

Gasparini, G. \& Margolies, L. (1977). Arquitectura inka (Universidad Central de Venezuela, Ed.). Caracas, Venezuela: Centro de Investigaciones Históricas Estéticas, Facultad de Arquitectura y Urbanismo.

González Moreno-Navarro., A. (2007, diciembre). Intervención y experiencias: restaurar es reconstruir. A propósito del nuevo monasterio de Sant Llorenç de Guardiola de Berguedà (Ed. semestral). E-RPH, 2-19.

Guerra, Y. (2017, febrero). Plano Centro Histórico. Ubicación puente de La Almudena. Cusco, Perú: s.e.

Hayakawa Casas, J. C. (2002). Restauración Monumental en Lima. Periodo 1920-1990. Tecnia, 43-53.

Instituto Nacional de Cultura. (1996). Plano más antiguo del Cusco, 1643 [afiche]. Cusco, Perú: Autor. 
Instituto Nacional de Cultura. (2007). Documentos fundamentales para el Patrimonio Cultural. Lima, Perú: Autor.

Iturria, V., Tuler, S., Ponce, N. \& Sessa, E. (2009, febrero). Teorías de la conservación: preceptos internacionales aplicados al estudio de obras de referencia dentro del patrimonio industrial. Universidad Nacional de La Plata - Comisión de Investigaciones Científicas de la Provincia de Buenos Aires. Recuperado de: http://sedici.unlp.edu.ar.

Montaner, J. M. (2002). Arquitectura y crítica. Barcelona, España: Gustavo Gili.

Municipalidad Provincial del Cusco. (2005). Plan maestro del centro histórico del Cusco. Cusco, Perú: Autor.

Novacovsky, A. (2001). Consideraciones metodológicas para la intervención en el patrimonio construido. En Curso de capacitación y transferencia de tecnología para la conservación de edificios de valor histórico - monumental (pp. 115-120). Mar del Plata, Argentina: s.e.

Oficina Técnica del Centro Histórico del Cusco. (2005). Plano eje procesional. Cusco, Perú: Municipalidad del Cusco - Agencia Española de Cooperación Internacional.

Organización de las Naciones Unidas para la Educación, Ciencia y Cultura. (1931). Carta de Atenas para la restauración de monumentos históricos. Atenas, Grecia: Autor.

Proyecto Qhapaq Ñan. (2003). Informe anual del Área de Investigación del proyecto Qhapaq Ñan, IA-DAG-PQÑ-AI-INC/2003 (D. Amado Gonzales, Coord.). Cusco, Perú: Instituto Nacional de Cultura.

Proyecto Qhapaq Ñan. (2003). Restauración y puesta en valor del Puente de La Almudena. Cusco, Perú: Instituto Nacional de Cultura.

Rodríguez Larraín Echecopar, M. (2014). Intervenciones en el centro histórico de Lima a partir de su declaratoria como patrimonio cultural de la humanidad. Devenir, (1), 146-149.

Rostworowski, M. (2004). Incas. Enciclopedia temática del Perú. Lima, Perú: El Comercio.

Sola-Morales, I. (2001). Teoría de la intervención arquitectónica - 1982 (Instituto Andaluz Histórico, Ed.). Boletín del Patrimonio Histórico Instituto Andaluz del Patrimonio Histórico (37), 47-52.

Universidad Nacional San Antonio Abad del Cusco. (1986). Planos del siglo XVIII. Archivo Regional del Cusco, 18. 